\title{
Chronic Inflammatory Demyelinating Polyneuropathy
}

National Cancer Institute

\section{Source}

National Cancer Institute. Chronic Inflammatory Demyelinating Polyneuropathy. NCI

Thesaurus. Code C84636.

An immunologic inflammatory disorder characterized by loss of myelin in the peripheral nerves. Patients present with progressive weakness and loss of sensory function in the legs and arms. 